\title{
BMJ Open Managing violence against healthcare personnel in the emergency settings of Pakistan: a mixed methods study
}

\author{
Muhammad Naseem Khan (10 , ${ }^{1}$ Ikram Khan, ${ }^{1}$ Zia Ul-Haq, ${ }^{1}$ Mirwais Khan, ${ }^{2}$ \\ Faryal Baddia, ${ }^{2}$ Fayaz Ahmad, ${ }^{1}$ Salman Khan ${ }^{2}$
}

To cite: Khan MN, Khan I, Ul-Haq Z, et al. Managing violence against healthcare personnel in the emergency settings of Pakistan: a mixed methods study. BMJ Open 2021;11:e044213. doi:10.1136/ bmjopen-2020-044213

- Prepublication history for this paper is available online. To view these files, please visit the journal online (http://dx.doi. org/10.1136/bmjopen-2020044213).

Received 13 0ctober 2020 Accepted 19 May 2021

Check for updates

(C) Author(s) (or their employer(s)) 2021. Re-use permitted under CC BY-NC. No commercial re-use. See rights and permissions. Published by BMJ.

${ }^{1}$ Institute of Public Health \& Social Sciences, Khyber Medical University, Peshawar, Khyber Pakhtunkhwa, Pakistan

${ }^{2}$ International Committee of the Red Cross, Geneve, GE, Switzerland

Correspondence to Dr Muhammad Naseem Khan; drnasim@kmu.edu.pk

\section{ABSTRACT}

Objectives The primary objective of this study was to evaluate the effectiveness of a half-day training on de-escalation of violence against healthcare personnel regarding prevention and management of violence incidents versus a similar tertiary-level hospital with no such training. Secondary objectives were to compare the overall satisfaction, burnout, fear of violence and confidence in coping with patients' aggression of the healthcare personnel in the two hospitals.

Design Mixed method design, with a comparative crosssectional (quantitative) and focus group discussions (qualitative) components.

Setting Emergency departments of the two tertiary care hospitals in district Peshawar over 6 months starting from May 2018.

Participants Healthcare personnel in the emergency departments of the two hospitals (trained vs untrained). Outcome measures Violence exposure (experienced/ witnessed) assessed through a previously validated tool in the past 5 months. Burnout, confidence in coping with patient aggression and overall job satisfaction were also assessed through validated tools. The qualitative component explored the perceptions of healthcare personnel regarding the management of violence and the importance of training on de-escalation of violence through focus group discussions in the two hospitals.

Results The demographic characteristics of the healthcare personnel within the two hospitals were quite similar. The de-escalation training did not lead to a reduction in the incidences of violence; however, confidence in coping with patient aggression and the overall satisfaction were significantly improved in the intervention hospital. The de-escalation training was lauded by the respondents as led to an improvement in communication skills, and the healthcare personnel suggested for scale-up to all the cadres and hospitals. Conclusion The study found significant improvements in the confidence of healthcare personnel in coping with patient aggression, along with better job satisfaction and less burnout in the intervention hospital following the deescalation training.

\section{INTRODUCTION}

Workplace violence faced by healthcare personnel has become one of the most critical health and safety issues worldwide. ${ }^{12}$

\section{Strengths and limitations of this study}

- Training healthcare personnel on the de-escalation of violent events has shown promising results; however, little has been done in Pakistan to develop and test a locally develop training module on the deescalation of violent events.

- This half-day brief training has shown promising results and can be scaled up to manage violence in healthcare settings.

- One major limitation could be that the study was done in two different hospitals; there could be some differences in the patients and numbers presenting to the two.

According to the definition by US National Institute for Occupational Safety and Health, 'workplace violence refers to violent acts, such as physical assaults and threats of assaults, directed towards persons at work or on duty. ${ }^{3}$ Workplace violence can occur in all work environments. However, because its incidence increases significantly under stressful circumstances, medical professionals are considered a highrisk population due to their close and first contact with patients and their relatives. Nurses, nursing assistants and physicians were most frequently assaulted while psychiatry department was the most frequent site of violent incidents followed by emergency department and geriatric wards. ${ }^{4}$

Workplace violence against healthcare takes many forms, including verbal abuse, aggression, harassment, bullying and physical violence. It also involves various types of perpetrators such as patients, patients' relatives and visitors, coworkers and others. ${ }^{5-7}$ Similar findings were reported by a mixed method study with 27 Italian nurses involved in the triage area of an emergency department. Ninety-six per cent of the nurses suffered an episode of violence during the previous year. Sixty-two per cent of the perpetrators were patient's relatives and friends. In 
$31 \%$ cases, the aggressor was a male patient. Nurses were of the opinion that abuse is an inevitable part of their job and exposure to workplace violence in triaging had significant consequences on their psychological wellbeing and behaviour at work and at home. ${ }^{8}$ Workplace violence remains a significant public health problem and has affected healthcare personnel in the developing as well as the developed world. ${ }^{5-79}$

Like other countries, the situation in Pakistan is also very dismal. A nationwide study conducted in the emergency departments of nine tertiary care hospitals from the three provinces of Pakistan found that more than three-fourth of the physicians-in-training had faced violence from patients and their relatives in the 2 months preceding the survey. ${ }^{9}$ High prevalence of verbal and physical violence was also reported in the emergency departments of four major tertiary care hospitals of the metropolitan city Karachi. The prevalence of verbal violence was more than two-third $(72.5 \%)$, while physical violence was experienced by $16.5 \%$ of the physicians and nurses in the previous 12 months. ${ }^{10}$ Healthcare workers of Karachi have witnessed similar higher rates of verbal or other types of violence, reported in different studies. ${ }^{11}{ }^{12}$ Likewise, a study revealed that half of the healthcare personnel in Peshawar had witnessed and/or experienced violence in the 12 months preceding the study. ${ }^{13}$

There is an immediate need for effective interventions for the prevention and management of violent incidents in the hospitals as the issue is important and could affect the performance and overall satisfaction of the healthcare personnel. Literature supports the role of de-escalation training of healthcare personnel in coping with violent incidents and managing violent behaviours. ${ }^{14-16}$ A project aimed at improving staff perception of knowledge, skills, abilities, confidence and preparedness when managing violent patient behaviours using interprofessional simulation training that was conducted at an emergency department. ${ }^{17}$ Participants received computer-based training, simulation training on de-escalation and restraint application. The participants' perceptions were collected in a pre and post survey. A significant improvement was recorded in knowledge (21\%), skills (20\%), abilities $(19 \%)$, confidence $(20 \%)$ and preparedness $(30 \%)$. Satisfaction among nurses, patient care assistant and security staff was greater than social services staff. Similarly, in a cross-sectional survey conducted in 19 hospitals across six cities of China, healthcare professionals exposed to psychological violence identified the need for target training to strengthen competence of healthcare workers to respond to violence. ${ }^{18}$

Based on these lines, the International Committee of the Red Cross (ICRC), under the framework of its Healthcare in Danger initiative, in collaboration with a team of public health experts, developed and pilot tested a training manual on the de-escalation of violence for the healthcare personnel in Karachi. The content of the training included five modules: understanding violence (understanding the meaning, causes and consequences of violence against healthcare providers); the importance of active communication in healthcare (tips on active listening, empathic communication and breaking bad news); de-escalating violence in healthcare (identifying signs of aggression and tips to de-escalate them); stress and post-traumatic stress disorder (dealing with psychological trauma due to violence) and rights and responsibilities of healthcare providers. The training is delivered through effective teaching methods including brainstorming, small-group discussions, videos based on scenarios and role-plays.

The effectiveness of the training was assessed through a quasi-experimental study, and it was found that the training led to statistically significant improvement in the confidence of healthcare personnel in coping with the patient aggression in the intervention arm compared with the control arm. ${ }^{19}$

The same training was provided to the healthcare personnel of the emergency department of Lady Reading Hospital (LRH); the largest and busiest hospital of Khyber Pakhtunkhwa province, from August till December 2017. A total of 237 healthcare personnel were trained, including doctors, nurses, paramedics, technicians and all the nonmedical auxiliary staff of the emergency department. The current study was planned to evaluate the effectiveness of this training on de-escalation of violence against healthcare personnel versus a similar tertiary-level hospital with no training. Secondary objectives were to compare the overall satisfaction, burnout, fear of violence and confidence in coping with patients' aggression of the healthcare personnel. A subsample of the healthcare personnel was also approached to explore their perceptions regarding training on de-escalation of violence. We hypothesise that personnel trained on de-escalation of violence in the emergency department will have better confidence in coping with patients aggression, better overall job satisfaction, less fear of violence and burnout and might experience a smaller number of violent incidents compared with healthcare personnel who were not trained.

\section{METHODS}

The study was conducted in the emergency department of two tertiary care hospitals, that is, LRH and Hayatabad Medical Complex (HMC), in district Peshawar, Pakistan over 6 months starting from May 2018. Both of these hospitals are tertiary-level hospitals within the provincial capital, that is, Peshawar district of Khyber Pakhtunkhwa. These hospitals are catering to a large catchment area and are referral hospitals for the entire province. On average, around 1500 to 1800 , patients are presenting to the emergency departments of both of these hospitals and are very busy and exposed to the incidences of violence.

This was a mixed-method study with quantitative and qualitative components. The quantitative component was explored through a comparative cross-sectional study within the emergency departments of the two hospitals. 
For the qualitative component, focus group discussions (FGDs) were conducted to explore the perceptions of healthcare personnel regarding the de-escalation of patients/relatives with aggression/violence and the need and importance of training on de-escalation of violence. Healthcare personnel who were trained on the de-escalation of violence in the emergency department of LRH were eligible for recruitment in the intervention hospital. Similarly, healthcare personnel working in the emergency department of the HMC were eligible from the control hospital. Healthcare personnel with less than 5 months of the overall experience in the emergency department were excluded from the study. For the quantitative component, a representative sample was collected from both the study hospitals. Assuming an overall reduction of $20 \%{ }^{19}$ in the incidence of violence in the trained healthcare personnel compared with the untrained, with $80 \%$ power and $5 \%$ level of significance, the minimum sample size required to conduct this study was 154 , that is, 77 in each group. Expecting a $20 \%$ nonresponse rate, we approached 100 participants in each hospital. Participants from each study site were selected using random sampling from the list of trained healthcare personnel in the intervention hospital and the list of all the healthcare personnel permanently deployed in the emergency department of the control hospital. Further stratification of doctors, nurses, paramedics, support and administrative personnel was also applied.

For the qualitative component, a subsample of healthcare personnel was conveniently approached for FGD. One FGD was conducted with the doctors and nurses of the intervention hospital regarding their needs for such training and the role it can play in the de-escalation of violence. While another FGD was conducted with the doctors and nurses of the control hospital regarding their coping mechanisms and the need for a formal training regarding de-escalation of violence.

\section{Measures}

Violence: violence was assessed through a previously used questionnaire by ICRC in a study in Karachi. ${ }^{12}{ }^{19}$ This tool had been developed by the Joint Programme on Workplace Violence in the Health Sector of the International Labour Office, the International Council of Nurses, the WHO and the Public Services International. ${ }^{20}$ Violence was defined as any individual or group's aggressive behaviour or exercise of power, which is socially nonacceptable, turbulent and often destructive. Mainly the violence was assessed through whether the respondent had experienced/witnessed any form of violence in the past 5 months. Physical violence was defined as the use of 'physical force against another person that results in physical, sexual or psychological harm and includes beating, kicking, slapping, stabbing, shooting, pushing, biting and pinching, among others. Verbal violence was defined as 'bullying, mobbing, harassment and verbal abuse that humiliates, degrades or otherwise indicates a lack of respect for the dignity and worth of an individual.
Confidence in coping with patient aggression: confidence levels of healthcare personnel in dealing with agitated patients were also measured using a scale adapted from 'Confidence in Coping with Patient Aggression Instrument' scale. The scale has been previously validated with strong internal consistency (Cronbach's alpha $=0.92$ ) and comprises of 10 items measured on a Likert scale with a total score of $40 .{ }^{21}$ Each question has a Likert scale response from 1 (very uncomfortable) to 4 (very comfortable). Therefore, the higher the score, the better the confidence of the healthcare personnel in dealing with the patient aggression.

Burnout: patients and relatives' aggression/violence towards healthcare personnel could lead to exhaustion and burnout in the healthcare personnel. Therefore, work-related burnout was an important aspect to be included in the current research study and was defined as 'a state of prolonged physical and psychological exhaustion, which is perceived as related to the person's work'. ${ }^{22}$ Burnout scale, comprising eight questions having a total score of 40, was used to assess burnout among healthcare personnel. Each question has a Likert scale response from 1 'never seldom or to a meagre degree' to 5 'always or to a very high degree'. Therefore, the higher the score, the more the burnout experienced by the respondent. The overall burnout was obtained by adding all the responses, and participants having a score of 20 or above categorised as a burnout.

Fear: for the current study, fear was defined as the concern that one might experience some form of violence (physical or verbal) while working as healthcare personnel in the emergency department. This was measured by adapting the tool used in the previous research. ${ }^{23}$ The responses were from strongly disagree to strongly agree regarding fear of physical or verbal violence.

Job satisfaction: job satisfaction was assessed through a single question as 'on the whole, how satisfied are you with your present job'. The responses were from very dissatisfied to very satisfied.

\section{Data collections and analysis}

The primary data collection tools were validated tools adapted for use in the current research study. A trained team of research assistants with experience in data collection conducted the fieldwork. Data were collected on a daily basis and handed over to the data entry team for entry/cleaning at the research site by the research coordinator. Any discrepancy and missing data were reported back immediately to the research assistants for clarification. Data entry was done in the Statistical Package for Social Sciences (SPSS) V.23. Double entry of data was done to check for any discrepancies, and corrections/cleaning were done after that. Data were analysed with measurement of mean and standard deviation (SD) for scale data and frequencies and percentages for categorical data. For the effectiveness of the training on de-escalation 
of violence, $\chi^{2}$ test was used, and associations were considered significant at $p$ value of $<0.05$.

For the qualitative component, the FGD guide was prepared based on the experiences shared by the Karachi team. FGDs were recorded and transcribed verbatim by the researchers. During and on completion of interviews, reflective notes and memos were taken. The resulting transcripts were coded by two researchers and cross checked by the principal investigator. Open coding of transcripts was used to identify important keywords, phrases and statements. From consequent stages of iterative readings, open and axial coding and common themes were developed.

Administrative approval was obtained from the administration of the sampled hospitals. Informed written consent was obtained from each participant after explaining the purpose of research and providing written information to participants. The right to withdrawal from the study at any time without providing a reason was reinforced to all participants during consent and before the conduct of the survey.

\section{Patient and public involvement}

No patients were involved in the current study. However, healthcare personnel were involved and participated in the study from the two hospitals. We also engaged the administration of the two hospitals to ensure their cooperation. The qualitative guide for the FGDs was also shared and their inputs were taken before the actual data collection. We have shared the findings of the study with the administration of the two hospitals.

\section{QUANTITATIVE RESULTS}

A total of 200 healthcare personnel were approached for participation in the current study with 100 each from the two hospitals.

\section{Demographic characteristics}

Table 1 compares the demographic characteristics of the healthcare personnel from the emergency departments of the two hospitals. There were no statistically significant differences in terms of age, gender, marital status, current position in the hospital (doctor, nurse, paramedics, support staff or administrative staff), total years of experience and years of experience in the emergency department between the healthcare personnel of the two hospitals.

\section{Violent incidents}

Table 2 compares the violent incidents experienced or witnessed by the healthcare personnel of the emergency departments of the two hospitals. There was no statistically significant difference between the participants exposure to violent incidents and the type of violence in the two hospitals, and $90 \%$ or above of the participants had experienced or witnessed violence
Table 1 Demographic characteristics of the study participants in the two hospitals

\begin{tabular}{|c|c|c|c|}
\hline Variable & $\begin{array}{l}\text { Intervention } \\
\text { hospital } \\
(\mathrm{N}=100) \\
\mathrm{n}(\%)\end{array}$ & $\begin{array}{l}\text { Control } \\
\text { hospital } \\
(\mathrm{N}=100) \\
\mathrm{n}(\%)\end{array}$ & P-value \\
\hline $\begin{array}{l}\text { Age } \\
\text { Mean (SD) }\end{array}$ & 33.52 (9.5) & $31.62(8.4)$ & $0.136 \dagger$ \\
\hline Men & $70(70)$ & $73(73)$ & 0.638 \\
\hline \multicolumn{4}{|l|}{ Marital status } \\
\hline Single & $35(35)$ & $41(41)$ & $0.327^{\star}$ \\
\hline Married & $63(63)$ & $59(59)$ & \\
\hline $\begin{array}{l}\text { Separated/ } \\
\text { divorced }\end{array}$ & $2(2)$ & $0(0)$ & \\
\hline \multicolumn{4}{|l|}{ Current position } \\
\hline Doctor & $5(5)$ & $5(5)$ & 0.999 \\
\hline Nurse & $30(30)$ & $30(30)$ & \\
\hline Paramedic & $27(27)$ & $28(28)$ & \\
\hline Support staff & $31(31)$ & $31(31)$ & \\
\hline Administration & $7(7)$ & $6(6)$ & \\
\hline $\begin{array}{l}\text { Years of work } \\
\text { experience in the } \\
\text { health sector } \\
\text { Mean (SD) }\end{array}$ & $7.56(8.26)$ & $8.20(8.05)$ & $0.579 \dagger$ \\
\hline $\begin{array}{l}\text { Years of work } \\
\text { experience } \\
\text { in casualty/ } \\
\text { emergency } \\
\text { Mean (SD) }\end{array}$ & $4.16(4.73)$ & 3.32 (3.71) & $0.168 \dagger$ \\
\hline
\end{tabular}

*Fisher exact where cell count is $<5$. †Independent sample t-test.

in some form in the last 5 months. Participants from the intervention hospital were significantly more concerned about violence compared with the control hospital.

\section{Confidence in coping with patient aggression}

Table 3 compares the confidence in coping with patient aggression by the healthcare personnel from the emergency department between the two hospitals. The tool has a cronbach's alpha of 0.81 regarding internal consistency of the items. There was a statistically significant difference in the overall confidence in coping with patient aggression, and the intervention hospital coped better following the training compared with the control hospital. In the individual items, a significant difference was observed in 'to intervene physically with an aggressive patient', 'effective techniques that you know for dealing with aggression' and 'able to meet the needs of an aggressive patient'. All these three individual items were significantly better in the intervention hospital compared with the control hospital. 
Table 2 Violent incidents in the two study hospitals

Intervention
hospital
$(\mathrm{N}=100)$

\begin{tabular}{|c|c|c|c|}
\hline Variable & n (\%) & n (\%) & P-value \\
\hline \multicolumn{4}{|c|}{$\begin{array}{l}\text { How concerned are you about violence in your current } \\
\text { workplace? }\end{array}$} \\
\hline $\begin{array}{l}\text { Not concerned } \\
\text { at all }\end{array}$ & $5(5)$ & $19(19)$ & 0.002 \\
\hline $\begin{array}{l}\text { Somewhat } \\
\text { concerned }\end{array}$ & $8(8)$ & $16(16)$ & \\
\hline Little concerned & $22(22)$ & $24(24)$ & \\
\hline Concerned & $43(43)$ & $24(24)$ & \\
\hline Very concerned & $22(22)$ & $17(17)$ & \\
\hline \multicolumn{4}{|c|}{ In the last 5 months experienced/witnessed violence } \\
\hline $\begin{array}{l}\text { Experienced } \\
\text { only }\end{array}$ & $8(8)$ & $3(3)$ & 0.198 \\
\hline Witnessed only & $11(11)$ & $18(18)$ & \\
\hline $\begin{array}{l}\text { Experienced } \\
\text { and witnessed }\end{array}$ & $74(74)$ & $69(69)$ & \\
\hline None & $7(7)$ & $10(10)$ & \\
\hline \multicolumn{4}{|c|}{ Type of violent incidents } \\
\hline $\begin{array}{l}\text { Verbal violence } \\
\text { only }\end{array}$ & $54(54)$ & $47(47)$ & 0.540 \\
\hline $\begin{array}{l}\text { Physical } \\
\text { violence only }\end{array}$ & $5(5)$ & $9(9)$ & \\
\hline $\begin{array}{l}\text { Verbal and } \\
\text { physical } \\
\text { violence }\end{array}$ & $34(34)$ & $34(34)$ & \\
\hline None & $7(7)$ & $10(10)$ & \\
\hline \multicolumn{4}{|c|}{ Perpetrator involved in the incident } \\
\hline None & $7(7)$ & $10(10)$ & 0.051 \\
\hline Patient himself & $0(0)$ & $5(5)$ & \\
\hline Attendants & $87(87)$ & $76(76)$ & \\
\hline General public & $1(1)$ & $4(4)$ & \\
\hline Hospital staff & $2(2)$ & $0(0)$ & \\
\hline $\begin{array}{l}\text { Combinations of } \\
\text { the above }\end{array}$ & $3(3)$ & $5(5)$ & \\
\hline
\end{tabular}

\section{Fear of workplace violence, burnout and overall satisfaction}

Table 4 compares the fear of workplace violence, burnout and overall satisfaction by the healthcare personnel from the emergency department between the two hospitals. The burout tool has a cronbach's alpha of 0.80 regarding internal consistency of the items. There was a statistically significant difference in the concern that the respondent will experience workplace physical violence while performing duties as healthcare personnel at the emergency department. This was more in the intervention arm compared with the control arm. Furthermore, burnout was more in the control hospital (65\%) compared with the intervention hospital (49\%). Regarding the overall satisfaction, more respondents were satisfied in the intervention hospital compared with the control hospital. One interesting finding was that the fear of physical violence was more in the intervention hospital compared with the control hospital.

\section{QUALITATIVE RESULTS}

Two FGDs were conducted, one each at the emergency department of intervention and control hospital. Six participants participated in each focus group, including two doctors, two male nurses, one female nurse and one medical technician.

\section{Intervention hospital}

From the focus group in intervention hospital, three potential themes emerged-the ground realities, improvement in communication skills and future recommendations. The number of codes and relevant quotes for respective themes are given in table 5 .

\section{The ground realities}

Healthcare personnel trained at the emergency department were reasonably satisfied with their learning from the training but uttered some inevitable and endogenous constraints of prevailing social system. Different circumstances and new stories were narrated by the healthcare personnel while sharing their experiences of verbal and physical violence. A major issue highlighted was the low literacy rate of community, which led to a multitude of problems and an ultimate predisposition to aggression and violence. One male nurse who was working at triage in the night shift said; "patients who can easily be discharged after an hour with us, insist on staying in the main medical hall till morning and say isn't this hospital meant for us' (R2). Over-crowding was another issue where 'every patient is escorted by half a dozen attendants, and everybody wants to know about the patient's condition, you know these people need training' (R4). Participants believed that temporary deficiency of material resources, especially at times of mass emergencies, also result in such incidents.

\section{Improvement in communication skills}

The participants unanimously expressed their positive responses about the training. Some of them believed that they already used to practice these communication skills in routine to deal with any unpleasant incident, but this training rendered their approach more systematic. 'This training was beneficial, and I learned a lot, some of the things we discarded and adopted others in our behaviours and communication skills after this training' (R1). They claimed a sense of vigilance and proactive approach to avoid any incidence of violence by prolonged talks, smiling face and patience. The participants were looking more confident about their counselling abilities and tackling different people according to the situation. They felt that now they listen more to patients and attendants (attendants are usually family members to support in the nursing care of 
Table 3 Confidence in coping with patient aggression

\begin{tabular}{|c|c|c|c|}
\hline Items & $\begin{array}{l}\text { Intervention hospital }(\mathrm{N}=100) \\
\text { Mean (SD) }\end{array}$ & $\begin{array}{l}\text { Control hospital }(\mathrm{N}=100) \\
\text { Mean (SD) }\end{array}$ & P-value \\
\hline $\begin{array}{l}\text { How comfortable are you in working with an } \\
\text { aggressive patient? }\end{array}$ & $2.61(0.65)$ & $2.52(0.82)$ & 0.392 \\
\hline $\begin{array}{l}\text { How good is your present level of training for } \\
\text { handling psychological aggression? }\end{array}$ & $2.99(0.58)$ & $2.88(0.80)$ & 0.264 \\
\hline $\begin{array}{l}\text { How able are you to intervene physically with an } \\
\text { aggressive patient? }\end{array}$ & $2.86(0.50)$ & $2.63(0.73)$ & 0.010 \\
\hline $\begin{array}{l}\text { How self-assured do you feel in the presence of } \\
\text { an aggressive patient? }\end{array}$ & $2.80(0.64)$ & $2.65(0.74)$ & 0.127 \\
\hline $\begin{array}{l}\text { How able are you to intervene psychologically } \\
\text { with an aggressive patient? }\end{array}$ & $2.82(0.48)$ & $2.79(0.61)$ & 0.699 \\
\hline $\begin{array}{l}\text { How good is your present level of training for } \\
\text { handling physical aggression? }\end{array}$ & $2.84(0.60)$ & $2.70(0.81)$ & 0.166 \\
\hline $\begin{array}{l}\text { How able are you to meet the needs of an } \\
\text { aggressive patient? }\end{array}$ & $2.94(0.37)$ & $2.77(0.58)$ & 0.015 \\
\hline $\begin{array}{l}\text { How able are you to protect yourself physically } \\
\text { from an aggressive patient }\end{array}$ & $2.88(0.57)$ & $2.70(0.82)$ & 0.074 \\
\hline Total score of the instrument & $28.32(3.21)$ & $26.78(4.57)$ & 0.006 \\
\hline
\end{tabular}

the patient and bringing of food/medicine) and consider this as an integral part of the plan in dealing with emergencies. 'We were least bothered about other people; our concern used to be the treatment of injured that's it-but now we try to understand people, now we work with people' (R6).

\section{Future recommendations}

The participants came up with two categories of recommendations-general recommendations and trainingspecific recommendations.

\section{General recommendations}

They felt that the community is not aware of the new changes in the emergency department especially different protocols; compartments of triage area like resuscitation room, waiting room, plaster room and prioritisation of patients according to the severity of the condition. They emphasised awareness and education of people through mass awareness campaigns and involvement of social media, which will potentially avert many incidents of violence. 'We need to educate our people first with the help of TV screens and Facebook or any awareness session for the community' (R4). They think that the administration should be involved for the implementation of one patient-1 attendant policy to avoid overcrowding. 'one patient-1 attendant policy is one big solution to many issues' (R3).

\section{Training-specific recommendations}

Participants urged that the hospital's security personnel and support staff like ward boys (ward boys are personnel responsible for daily ward-related activities like taking blood tests/reports to and from the laboratory) and sweepers (personnel for cleaning of hospitals wards and premises) must be trained on the de-escalation of violence. They believe these staff members are involved more in direct contact with people and yet have poor communication skills. They believed that lectures on communication skills imparted in training were of higher level, and in the future, these lectures should be based on some basic-level skills. One of the participants informed that more reallife scenarios should be used for demonstration during training. 'We already have a lot of such incidents with us. I think for demonstration purpose trainers should seek our help for designing some reality-based scenarios' (R6). One of the participants opined about time management as well. 'We have tough schedules; if we are called for 9:00 AM, then it must be started at 9:00 AM' (R1). Participants suggested that practical work should override theoretical work, and the session of training must be even more interactive. 'Typical lectures make you fall asleep; there must be activities' (R5).

\section{Control hospital}

From the focus group with healthcare personnel of the control hospital, two potential themes emerged-building a case for training and recommendations. The number of codes and relevant quotes for respective themes are given in table 6.

\section{Building a case for training sessions}

Some of the issues identified by the participants of this FGD were quite similar to those pointed out by the FGD 
Table 4 Fear of workplace violence, burnout and overall satisfaction among healthcare personnel

\begin{tabular}{|c|c|c|c|}
\hline Variable & $\begin{array}{l}\text { Intervention } \\
\text { hospital } \\
(\mathrm{N}=100) \\
\mathrm{n}(\%)\end{array}$ & $\begin{array}{l}\text { Control } \\
\text { hospital } \\
(\mathrm{N}=100) \\
\mathrm{n}(\%)\end{array}$ & P-value \\
\hline \multicolumn{4}{|c|}{$\begin{array}{l}\text { I am concerned that I will experience workplace physical } \\
\text { violence while performing my duties as a healthcare } \\
\text { personnel at the emergency department }\end{array}$} \\
\hline Strongly disagree & $11(11)$ & $22(22)$ & 0.028 \\
\hline Disagree & $38(38)$ & $22(22)$ & \\
\hline $\begin{array}{l}\text { Neither agree nor } \\
\text { disagree }\end{array}$ & $10(10)$ & $10(10)$ & \\
\hline Agree & $36(36)$ & $34(34)$ & \\
\hline Strongly agree & $5(5)$ & $12(12)$ & \\
\hline \multicolumn{4}{|c|}{$\begin{array}{l}\text { I am concerned that I will experience workplace verbal } \\
\text { violence while performing my duties as a healthcare } \\
\text { personnel at the emergency department }\end{array}$} \\
\hline Strongly disagree & $6(6)$ & $14(14)$ & 0.114 \\
\hline Disagree & $32(32)$ & $20(20)$ & \\
\hline $\begin{array}{l}\text { Neither agree nor } \\
\text { disagree }\end{array}$ & $11(11)$ & $9(9)$ & \\
\hline Agree & $40(40)$ & $40(40)$ & \\
\hline Strongly agree & $11(11)$ & $17(17)$ & \\
\hline \multicolumn{4}{|l|}{ Burnout } \\
\hline $\begin{array}{l}\text { Burnout (score } 20 \\
\text { or above) }\end{array}$ & $49(49)$ & $65(65)$ & 0.022 \\
\hline $\begin{array}{l}\text { No Burnout (score } \\
\text { of } 19 \text { or less) }\end{array}$ & $51(51)$ & $35(35)$ & \\
\hline \multicolumn{4}{|l|}{ Overall satisfaction } \\
\hline Very dissatisfied & $3(3)$ & $8(8)$ & $<0.001$ \\
\hline A little dissatisfied & $8(8)$ & $9(9)$ & \\
\hline $\begin{array}{l}\text { Moderately } \\
\text { satisfied }\end{array}$ & 19 (19) & $45(45)$ & \\
\hline Very satisfied & $70(70)$ & $38(38)$ & \\
\hline
\end{tabular}

of the intervention hospital, like overcrowding, insufficient human and material resources, the literacy level of community and misuse of emergency services. The participants informed about some of their skills and practices of daily routine, which include counselling, courtesy and politeness, empathy, prioritising seriously ill patients and informing others about the fact. One doctor admitted the fact that 'doctor's behaviour matters more than anything, illiterate people after being referred and re-referred from different hospitals end up with us, and then we talk to them rudely- this is not fair' (R2). Some participants claimed their strength in breaking bad news and listening more to extra aggressive people. One senior fellow reported about the young healthcare personnel that 'house officers and freshmen are very disrespectful when I compare it with our times, they don't respect even their seniors and I have seen them how rudely they deal with poor and elderly patients and attendants' (R3). The participants strongly recommended training on de-escalation of violence for the youngsters and behaviour change communication skills for all the staff.

\section{Recommendations}

All the participants urged the need for training on de-escalation of violence but simultaneously emphasised the involvement of community (with vigorous advocacy and awareness campaigns) and administration of hospital (for renovation and cosiness of emergency environment). One participant stated, 'training is very much needed; we have skills but when not in practice, we forget to apply it at that time' (R1). 'Training and regular refresher courses sensitise and polish your communication skills, so training is a must and especially for junior staff who have less experience of public dealing' (R4). This focus group discoursed that training sessions should impart little theory or lecture-based knowledge, but more practical and scenario-based activities for which support can be sought from experts within the hospital to design real-life demonstrations. They also think that 'such trainings should become a regular part of house-job for doctors and internship programs for paramedical staff' (R2).

\section{DISCUSSION}

This was a mixed methods study of the emergency healthcare personnel of one tertiary care hospital compared with a control hospital of a similar level. This study adds to the existing knowledge regarding effectiveness of de-escalation of violence training in managing workplace violence in healthcare settings by additionally exploring the effects of the training on job satisfaction and burnout. There were no statistically significant differences in the basic demographic characteristics between the healthcare personnel of the emergency departments of the two hospitals. The main findings of the study showed that the de-escalation training conducted in the intervention hospital led to the healthcare personnel having increased confidence in dealing with patient aggression compared with the control hospital with no such training. Similar improvement in knowledge and confidence to manage aggression and violence were reported in studies conducted in Australia. ${ }^{24}$ Improvement in attitudes of nurses towards aggressive behaviour has been reported following participation in a prevention and management of aggressive behaviour programme. ${ }^{25}$ The overall satisfaction was more in the intervention arm compared with the control arm. A study conducted in Stockholm, Sweden showed that workplace environment and healthcare providers' attitudes are influenced following violence prevention and management training. ${ }^{26}$ Similarly, the burnout of healthcare personnel was more in the control hospital compared with the intervention hospital. However, there was not any statistically significant findings in the incidence of violent events experienced or witnessed in the preceding 5 months interval between the healthcare personnel of the two hospitals. 


\begin{tabular}{|c|c|c|c|}
\hline Theme & Number of codes & Relevant quote & Recommendations/interventions \\
\hline The ground realities & 11 & $\begin{array}{l}\text { Every patient is escorted by half a dozen } \\
\text { attendants and everybody wants to know } \\
\text { about the patient's condition, you know } \\
\text { these people need training (R4) }\end{array}$ & $\begin{array}{l}\text { As recommended by the } \\
\text { participants themselves, one } \\
\text { patient one attendant policy should } \\
\text { be adopted strictly. }\end{array}$ \\
\hline $\begin{array}{l}\text { Improvement in } \\
\text { communication skills }\end{array}$ & 09 & $\begin{array}{l}\text { We were least bothered about other } \\
\text { people; our concern used to be the } \\
\text { treatment of injured-that's it-but now we } \\
\text { try to understand people, now we work } \\
\text { with people (R6). }\end{array}$ & $\begin{array}{l}\text { Training on de-escalation of } \\
\text { violence should be scaled up. }\end{array}$ \\
\hline Future recommendations & 13 & $\begin{array}{l}1 \text { patient- } 1 \text { attendant policy is one big } \\
\text { solution to many issues (R3). } \\
\text { We have tuff schedules; if we are called } \\
\text { for 9:00 AM then it must be started on } \\
\text { 9:00 (R1) }\end{array}$ & $\begin{array}{l}\text { Training timing should be strictly } \\
\text { followed as doctors in hospitals } \\
\text { have tough schedule and are } \\
\text { extremely busy. Moreover, the } \\
\text { hospital management should } \\
\text { ensure that all participants are } \\
\text { informed and present on time. }\end{array}$ \\
\hline
\end{tabular}

Interestingly, the intervention hospital healthcare personnel feared workplace physical violence more compared with the control hospital, and this finding was statistically significant. This might be that the hospital healthcare personnel were sensitised by the training and, therefore, feared the violence more. The qualitative results yielded positive feedback of the healthcare personnel regarding the de-escalation training and urged for refreshers and widening the scale of the training leading to the involvement of the support staff, including administration.

Similar results have been reported in Karachi, where the same intervention improved confidence in coping with patients' aggression. ${ }^{19}$ The study did not achieve any improvements in the reduction of the incidences of violence in the 5 months following the training on de-escalation of violence. Improved confidence in coping with patient aggression is reported in the literature following training on communication skills and managing patient aggression. ${ }^{27}$ A narrative literature review of nine studies also supports improvement in communications and dealing with patient aggression following training on aggression management and communication skills. ${ }^{28}$

Lack of effect on the incidences of violence in the current study and Karachi ${ }^{19}$ could be because the training improved the skills of the healthcare personnel; however, there is no component or involvement of the patients/ relatives. A holistic approach might be required for the reduction of the incidences of violence, as pointed out by the respondents in the FGDs. They pointed out that awareness of the public regarding respect for the healthcare personnel should be raised through print and electronic media. One important area that also leads to frustration and initiation of the incidences of violence is lack of awareness regarding the condition of patients and the whole process in the management of patients presenting to the emergency department. On the whole, these are issues related to communication. To address this gap, information tools were developed and implemented in the Ballarat Health Service Emergency Department of Victoria Australia. The information tools included improved signage with information on the processes a

Table 6 Control Hospital

\begin{tabular}{|c|c|c|c|}
\hline Theme & $\begin{array}{l}\text { Number of } \\
\text { codes }\end{array}$ & Relevant quote & Recommendations/interventions \\
\hline $\begin{array}{l}\text { Building a case for } \\
\text { trainings }\end{array}$ & 14 & $\begin{array}{l}\text { doctor's behaviour really matters more than } \\
\text { anything, illiterate people after being referred and } \\
\text { re-referred from different hospitals end up with us } \\
\text { and then we talk to them rudely- this is not fair (R2). } \\
\text { House officers and freshmen are very disrespectful } \\
\text { when I compare it with our times, they don't } \\
\text { respect even their seniors and I have seen them } \\
\text { how rudely they deal with poor and elderly patients } \\
\text { and attendants (R3) }\end{array}$ & $\begin{array}{l}\text { Training on de-escalation of } \\
\text { violence should be scaled up } \\
\text { specifically involving young doctors. }\end{array}$ \\
\hline Recommendations & 10 & $\begin{array}{l}\text { Training is very much needed; we have skills but } \\
\text { when not in practice we forget to apply it at that } \\
\text { time (R1). }\end{array}$ & $\begin{array}{l}\text { Practical training with local case } \\
\text { scenarios in an interactive format. }\end{array}$ \\
\hline
\end{tabular}

doctor's behaviour really matters more than anything, illiterate people after being referred and re-referred from different hospitals end up with us and then we talk to them rudely- this is not fair (R2). House officers and freshmen are very disrespectful when I compare it with our times, they don't respect even their seniors and I have seen them how rudely they deal with poor and elderly patients and attendants (R3) when not in practice we forget to apply it at that 
patient could follow, a waiting room video explaining a patient's journey in the emergency department, a patient pamphlet and time to wait. These enhanced information initiatives about ED processes and waiting time were well received by patients and carers, leading to a better understanding of ED processes and nurses perceived a reduction in episodes of aggressive behaviour. ${ }^{29}$ These interventions could be adapted in our settings as no such information is available to the patient/attendant, which might trigger their frustrations and initiation of the violent incidents. Similar recommendations were reported in a qualitative study of the nurse's perceptions regarding patient aggression. ${ }^{30}$

The overall satisfaction was better in the intervention hospital, and less burnout was reported, which points towards the impact of the de-escalation training on the overall working environment. Such kind of violent events have a negative impact on the overall satisfaction and burnout of healthcare personnel. ${ }^{31-33}$ Violent events demotivate the healthcare personnel and increases the likelihood of burnout, as evident in the current study. Burnout might lead to abrupt decisions from the healthcare personnel that could be even harmful for the patients. Therefore, every effort should be made to tackle the issue of violence against healthcare and provides a conducive environment to the healthcare personnel. This will enable them to better focus on the management of patients rather than to be concerned about their safety and security.

There were few inherent limitations in the study and the most important being that the study was done in two different hospitals. Although both of these are tertiary-level hospitals, however, there could be some differences in the patients and numbers presenting to the two. Therefore, in future studies, the details of the patients presenting in these hospitals should be included to control for the confounding effects. Additionally, a follow-up study would have been better to report the incidences of violence before and after the de-escalation training. The study reported $100 \%$ response rate as the data of participants declining/ refusing participation were not collected.

To conclude, the current study found significant improvements in the confidence of healthcare personnel in coping with patient aggression, along with better job satisfaction and less burnout in the intervention hospital following the de-escalation training for the healthcare personnel of the emergency department. However, a more holistic approach is required to enhance awareness of patients, attendants and the general public regarding the respect of healthcare personnel along with interventions in the healthcare system like awareness of the status of the patient, process and procedures in their management.

\section{Twitter Muhammad Naseem Khan @khannaseemkhan}

Acknowledgements We are grateful to all the healthcare personnel for their time and involvement in the study. We are also very grateful to our team of data collectors and healthcare administration. Lastly, we are thankful to the management of International Committee of the Red Cross, Pakistan for the technical and financial support of the study.

Contributors MNK, IK, ZU-H and MK conceived the idea of this research study and participated in its coordination. MNK, IK, ZUH, FB, FA and SK conducted field research activities and were involved in the data collection, cleaning and initial analysis. All authors contributed towards preparing the first draft as well as editing and reviewing of the subsequent drafts. The authors read and approved the final manuscript.

Funding This study was conducted under the framework of the Healthcare in Danger (HCiD) initiative of the International Committee of the Red Cross (ICRC). The funding body has no role in the design of the study and collection, analysis and interpretation of the data and in writing of the manuscript.

Competing interests None declared.

Patient and public involvement Patients and/or the public were involved in the design, or conduct, or reporting, or dissemination plans of this research. Refer to the Methods section for further details.

Patient consent for publication Not required.

Ethics approval The study received ethical approval from the Ethics Board, Khyber Medical University, Reference number: DIR/KMU-EB/TE/000665.

Provenance and peer review Not commissioned; externally peer reviewed.

Data availability statement Data are available in a public, open access repository. Extra data can be accessed via the Dryad data repository at http://datadryad.org/ with the doi:10.5061/dryad.8cz8w9gn9.

Open access This is an open access article distributed in accordance with the Creative Commons Attribution Non Commercial (CC BY-NC 4.0) license, which permits others to distribute, remix, adapt, build upon this work non-commercially, and license their derivative works on different terms, provided the original work is properly cited, appropriate credit is given, any changes made indicated, and the use is non-commercial. See: http://creativecommons.org/licenses/by-nc/4.0/.

ORCID iD

Muhammad Naseem Khan http://orcid.org/0000-0002-0484-0985

\section{REFERENCES}

1 Nikathil S, Olaussen A, Gocentas RA, et al. Review article: workplace violence in the emergency department: a systematic review and meta analysis. Emerg Med Australas 2017;29:265-75.

2 Liu J, Gan Y, Jiang H, et al. Prevalence of workplace violence against healthcare workers: a systematic review and meta-analysis. Occup Environ Med 2019;76:927-37.

3 Occupational Safety \& Health Administration. Workplace Violence in Healthcare: Understanding the Challenge [Internet]. Available: https:// www.osha.gov/Publications/OSHA3826.pdf [Accessed 26 Jun 2020].

4 Ferri P, Silvestri M, Artoni C, et al. Workplace violence in different settings and among various health professionals in an Italian General Hospital: a cross-sectional study. Psychol Res Behav Manag 2016;9:263-75.

5 Bourn J, Maxfield A, Terry A. A safer place to work: protecting NHS hospital and ambulance staff from violence and aggression. Natl Audit Off Lond 2003;54.

6 Gacki-Smith J, Juarez AM, Boyett L, et al. Violence against nurses working in US emergency departments. J Nurs Adm 2009;39:340-9.

7 Joa TS, Morken T. Violence towards personnel in out-of-hours primary care: a cross-sectional study. Scand J Prim Health Care 2012;30:55-60.

8 Ferri P, Stifani S, Accoto A, et al. Violence against nurses in the triage area: a mixed-methods study. J Emerg Nurs 2020;46:384-97.

9 Mirza NM, Amjad Al, Bhatti ABH, et al. Violence and abuse faced by junior physicians in the emergency department from patients and their caretakers: a nationwide study from Pakistan. J Emerg Med 2012;42:727-33.

10 Zafar W, Siddiqui E, Ejaz K, et al. Health care personnel and workplace violence in the emergency departments of a volatile metropolis: results from Karachi, Pakistan. J Emerg Med 2013;45:761-72.

11 Nayyer I, Yousuful-Islam M, Farooq MS. Workplace violence experienced by doctors working in government hospitals of Karachi. J Coll Physicians Surg Pak 2014;24:698-9. 
12 Baig LA, Shaikh S, Polkowski M, et al. Violence against health care providers: a mixed-methods study from Karachi, Pakistan. J Emerg Med 2018;54:558-66.

13 Khan MN, Haq ZU, Khan M, et al. Prevalence and determinants of violence against health care in the metropolitan city of Peshawar: a cross sectional study. BMC Public Health 2021;21:1-11.

14 Oostrom JK, van Mierlo $\mathrm{H}$. An evaluation of an aggression management training program to cope with workplace violence in the healthcare sector. Res Nurs Health 2008;31:320-8.

15 Richmond J, Berlin J, Fishkind A, et al. Verbal De-escalation of the agitated patient: consensus statement of the American association for emergency psychiatry project beta De-escalation Workgroup. WestJEM 2012;13:17-25.

16 Deans $C$. The effectiveness of a training program for emergency department nurses in managing violent situations, 2004.

17 Krull W, Gusenius TM, Germain D, et al. Staff perception of interprofessional simulation for verbal de-escalation and restraint application to mitigate violent patient behaviors in the emergency department. J Emerg Nurs 2019;45:24-30.

18 Zhao S, Liu H, Ma H, et al. Coping with workplace violence in healthcare settings: social support and strategies. Int J Environ Res Public Health 2015;12:14429-44.

19 Baig L, Tanzil S, Shaikh S, et al. Effectiveness of training on deescalation of violence and management of aggressive behavior faced by health care providers in a public sector hospital of Karachi. Pak J Med Sci 2018;34:294

20 Ilo I, WHO P. Joint programme on workplace violence in the health sector. In: Workplace violence health Sect Ctry case StudyQuestionnaire. 14. Geneva, 2003.

21 Nau J, Halfens R, Needham I, et al. The de-escalating aggressive behaviour scale: development and psychometric testing. J Adv Nurs 2009;65:1956-64.

22 Borritz M, Rugulies R, Bjorner JB, et al. Burnout among employees in human service work: design and baseline findings of the PUMA study. Scand J Public Health 2006;34:49-58.
23 Barling J, Rogers AG, Kelloway EK. Behind closed doors: in-home workers' experience of sexual harassment and workplace violence. $J$ Occup Health Psychol 2001;6:255-69.

24 Grenyer BFS, Ilkiw-Lavalle O, Biro P, et al. Safer at work: development and evaluation of an aggression and violence minimization program. Aust N Z J Psychiatry 2004;38:804-10.

25 Collins J. Nurses' attitudes towards aggressive behaviour, following attendance at 'The Prevention and Management of Aggressive Behaviour Programme'. J Adv Nurs 1994;20:117-31.

26 Björkdahl A, Hansebo G, Palmstierna T. The influence of staff training on the violence prevention and management climate in psychiatric inpatient units. J Psychiatr Ment Health Nurs 2013;20:396-404.

27 Glass N, Hanson GC, Anger WK, et al. Computer-Based training (CBT) intervention reduces workplace violence and harassment for homecare workers. Am J Ind Med 2017;60:635-43.

28 Heckemann B, Zeller A, Hahn S, et al. The effect of aggression management training programmes for nursing staff and students working in an acute hospital setting. A narrative review of current literature. Nurse Educ Today 2015;35:212-9.

29 See JA, Catterson P. Can improving information to patients about emergency department processes reduce aggressive behaviour towards staff? Emerg Med Australas 2017;29:597-8.

30 Angland S, Dowling M, Casey D. Nurses' perceptions of the factors which cause violence and aggression in the emergency department: a qualitative study. Int Emerg Nurs 2014;22:134-9.

31 Yang BX, Stone TE, Petrini MA, et al. Incidence, type, related factors, and effect of workplace violence on mental health nurses: a crosssectional survey. Arch Psychiatr Nurs 2018;32:31-8.

32 Zhao S-H, Shi Y, Sun Z-N, Sun Zhi-Nan, et al. Impact of workplace violence against nurses' thriving at work, job satisfaction and turnover intention: a cross-sectional study. J Clin Nurs 2018;27:2620-32.

33 Hamdan M, Hamra Asma'a Abu. Burnout among workers in emergency departments in Palestinian hospitals: prevalence and associated factors. BMC Health Serv Res 2017;17:1-7. 